$\begin{array}{ll} & \text { Etnográfica } \\ \text { etnográfica } & \text { Revista do Centro em Rede de Investigação em }\end{array}$

Antropologia

vol. $20(2) \mid 2016$

Vol. $20(2)$

\title{
O santo, a face e o outro: quando Cristo e Tiradentes se encontram em Ouro Preto
}

The saint, the face and the other: when Christ and Tiradentes meet in Ouro Preto

\section{Edilson Pereira}

\section{(2) OpenEdition}

\section{Journals}

\section{Edição electrónica}

URL: https://journals.openedition.org/etnografica/4314

DOI: 10.4000/etnografica.4314

ISSN: 2182-2891

\section{Editora}

Centro em Rede de Investigação em Antropologia

\section{Edição impressa}

Data de publição: 1 junho 2016

Paginação: 363-386

ISSN: 0873-6561

\section{Refêrencia eletrónica}

Edilson Pereira, «O santo, a face e o outro: quando Cristo e Tiradentes se encontram em Ouro Preto», Etnográfica [Online], vol. 20 (2) | 2016, posto online no dia 29 junho 2016, consultado o 11 fevereiro 2022. URL: http://journals.openedition.org/etnografica/4314 ; DOI: https://doi.org/10.4000/ etnografica. 4314

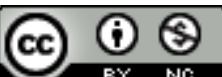

Etnográfica is licensed under a Creative Commons Attribution-NonCommercial 4.0 International License. 


\section{O santo, a face e o outro: quando Cristo e Tiradentes se encontram em Ouro Preto}

\section{Edilson Pereira}

Abordo neste artigo uma imagem particular de Cristo que participa da reencenação da via-crúcis durante a Semana Santa na cidade de Ouro Preto, em Minas Gerais (Brasil). A partir da história da necessidade de substituição da cabeça dessa imagem, observo como a busca de uma nova "face" para tal figura coloca em evidência questões próximas àquelas desenvolvidas por Georges Bataille e Michael Taussig para tratar da porosidade dos limites entre sagrado e profano e das transgressões que os reforçam mutuamente. Ao me aproximar de tais autores, abordo o tema da fragmentação do corpo humano para tratar de outro mártir celebrado em Ouro Preto: Tiradentes, herói político nacional que foi, em seu culto cívico, progressivamente cristianizado. Reflito, ao fim, sobre as múltiplas implicações que os rostos e corpos (ausentes) dessas figuras - Cristo e Tiradentes - produziram entre si no curso de diferentes rituais e momentos históricos, incluindo o contexto festivo católico.

PALAVRAS-CHAVE: transgressão, Semana Santa, Ouro Preto, Tiradentes, corpo sagrado.

The saint, the face and the other: when Christ and Tiradentes meet in Ouro Preto - In this article, I examine a particular Christ's effigy that participates in the re-enactment of the Via Crucis during the Holy Week in Ouro Preto, Minas Gerais (Brazil). Analysing the history of the replacement of the statue's head, I observe how the native search for a new "face" to this figure highlights Georges Bataille's and Michael Taussig's questions about the porosity of boundaries between sacred and profane, as well as the transgressions that mutually reinforce them. Their theories allow me to approach the theme of the fragmentation of the human body and to explore the civic cult held in Ouro Preto to Tiradentes, a Brazilian political hero who became progressively a Christianised martyr. To conclude, I outline multiple implications produced by those (absent) faces and bodies - of Christ and Tiradentes - during different rituals and in different historical moments, including the Catholic festive context.

KEYWORDS: transgression, Holy Week, Ouro Preto, Tiradentes, sacred body.

PEREIRA, Edilson (edilperei@yahoo.com.br) - Departamento de Antropologia, Programa de Pós-Graduação em Ciências Sociais, Universidade do Estado do Rio de Janeiro (UERJ), Brasil. 
NESTE ARTIGO, ABORDO ALGUNS DADOS DE PESQUISA QUE ANALISO após a conclusão da minha tese de doutorado, na qual discorri sobre as dinâmicas sociais e transformações rituais que caracterizam a celebração da Semana Santa na cidade de Ouro Preto, em Minas Gerais (Pereira 2014). ${ }^{1}$ Conhecida por muitos em função de seu patrimônio histórico e arquitetônico, que remete aos desdobramentos do chamado Ciclo do Ouro brasileiro - contexto econômico e social que datava do século XVIII -, a Ouro Preto do presente tem em festas como a Semana Santa um momento importante de sua vida social. Junto à atração de turistas para a cidade, interessados na chamada "Paixão de Cristo à moda mineira" ${ }^{2}$ - que seria herdeira de uma estética barroca e de "tradições" mantidas na sua forma de festejar a Páscoa cristã -, esse período festivo coloca em evidência tensões e delimitações sociais operativas na divisão de bairros e paróquias locais. Na minha pesquisa, entre os anos 2009 e 2013 (com incursões de trabalho de campo realizadas antes, durante e após a festa), eu observei os principais personagens que permitem entrever e compreender as redes que se estabelecem por conta da Semana Santa e, igualmente, os símbolos - religiosos, históricos, sociais - acionados nesse contexto. ${ }^{3}$ Entre as figuras abordadas estava evidentemente o Cristo, protagonista de todo o drama reencenado no curso de cerimônias religiosas e procissões que ocupam praças do centro da cidade e atravessam seus bairros de um lado a outro. E é sobre ele que falarei aqui.

Ao desenvolver este exercício de análise, quero partir de alguns dados da minha pesquisa para avançar rumo a outros cenários que se ligam às representações cristãs da dor, da morte e do sacrifício e que se conectam a certos modos de sacralização. Igualmente, interessa-me observar a dinâmica associada à decomposição e à separação dos corpos considerados "santos" (bem como de suas partes constitutivas) do domínio da vida comum, ordinária - passando a ser alvo de "proteção" de certos museus. De modo sintético, pode-se dizer que a ideia global deste texto parte do intento de pensar como a história do Cristo,

I Versões preliminares deste texto foram apresentadas na III Jornada de Antropologia da Devoção, realizada no Museu Nacional/UfrJ, e no evento "Religiões, Materialidades, Espaços Públicos", que ocorreu na UFRGS, em abril e junho de 2015 respectivamente. Agradeço a Renata Menezes, Emerson Giumbelli, Lilian Gomes e Leonardo Dupin pelos comentários que contribuíram para desenvolver as ideias presentes no texto. Agradeço também aos pareceristas anônimos pelas valiosas sugestões.

2 Título da matéria no jornal carioca O Globo, no caderno "Boa Viagem", publicado em 25 de fevereiro de 2010 (disponível em < http://oglobo.globo.com/boa-viagem/semana-santa-paixao-de-cristo-moda-mi neira-3048979 > (última consulta em maio de 2016).

3 As idas a campo variaram em sua duração de acordo com o processo da pesquisa e as demandas por novas informações - com períodos de curta estadia, de uma semana, e outros de maior duração, com cerca de 80 dias ininterruptos, que se somavam em diferentes momentos ao longo de cada ano. Ao total, foram produzidas mais de cem entrevistas com gravador, além de dezenas horas de vídeo com entrevistas e registros da festa e, ainda, um acervo de mais de 4600 fotografias - de pessoas, artefatos, espaços e situações rituais. 
observada a partir de uma situação emblemática que envolve uma de suas representações materiais, isto é, um de seus ícones utilizados nos rituais da Semana Santa, pode nos conectar também com a materialidade, mesmo que ausente (conforme discutirei adiante), do corpo de outra figura particular. Esta última, ainda que exceda ao universo da toponímia do "religioso", também se destaca na história e nos rituais públicos que ocorrem na cidade de Ouro Preto. Ela nos mostra, complementarmente, como os sentidos associados à violência da paixão cristã e aos seus ícones podem exceder a esfera do religioso, contaminando as coisas e as pessoas que se aproximem do seu entorno. Tenho por objetivo, portanto, realizar um movimento gradual que nos leve da figura do Cristo e de sua face sagrada, daquele que é tomado como a "cabeça" da Igreja, rumo a uma alteridade, a um outro tipo de santo cujas correspondências com aquele nos permitem perceber alguns modos de sua mútua afetação.

Assim, apresentarei primeiramente o contexto ouro-pretano no qual as imagens religiosas estão inseridas e destacarei as formas de relação que tendem ao reconhecimento de atributos humanos às mesmas, como parte de uma dinâmica de reconhecimento (por algumas pessoas) de sua subjetividade. A partir desse ponto, passo a abordar uma imagem em particular. A história contada sobre ela e o local onde ela é exposta nos permitirão, em seguida, refletir sobre uma forma contraditória - senão blasfema - de sua utilização ritual. Valendo-me, então, de reflexões que buscam compreender de modo positivo o caráter de fenômenos ambivalentes, ${ }^{4}$ tais como aqueles que se associam à noção de sagrado, revisito parte da teoria de autores como Georges Bataille (1987, 1990), e de alguns de seus atualizadores como Michael Taussig (1997, 1999), para pensar o chamado "poder do negativo". Em tal expressão, segundo esse último autor, estaria impressa a força que é observada nos atos blasfematórios (intencionais ou não) que, ao invés de efetivamente aniquilarem o mistério de algo sagrado, acabariam por reforçá-lo, ainda que obrigando-o a se reconfigurar de algum modo.

Na sequência, aproveito as reflexões sobre o Cristo para pensar um personagem brasileiro que após ser sacrificado também assumiu a máscara daquela persona sagrada. Para falar do mártir político nacional Tiradentes, revisitarei brevemente o seu histórico, a fim de mostrar como a sua consagração como herói remete a momentos e a interesses diversos e chega até o tempo presente (incluindo aí o da minha própria incursão de pesquisa de campo em Ouro Preto). Depois de refletir sobre ele e os corpos dos demais inconfidentes, voltarei finalmente à Semana Santa para encontrar esse "outro" dentro dos rituais cristãos. Deixarei, então, ao/à leitor/a a missão de descobrir as correspondências entre Cristo e ele no transcorrer do próprio texto. Ressalto, não obstante, que

4 Isto é, sem pressupor que tal característica - de ser ambíguo - seja uma forma de desvio em relação a determinada normalidade. Assumo tal aspecto como uma dimensão constitutiva do universo analisado. 
mais do que uma comparação entre essas duas figuras míticas para observar o que elas isoladamente teriam de semelhante entre si, me interessa sobretudo pensar o que há no espaço comum que foi sendo constituído entre elas.

\section{IMAGENS DA PAIXÃO OURO-PRETANA}

De modo comum a diversos outros locais, as representações materiais do Cristo em Ouro Preto se constituem tanto de ícones tridimensionais (talhados em madeira), quanto de alguns rapazes vinculados a grupos religiosos que encenam, durante a Semana Santa, os Autos da Paixão. A diferença entre esses dois tipos de "atores", todavia, vai além do caráter esculpido ou não de seus corpos. De um modo geral, os Cristos encenados por pessoas fazem parte de apresentações que percorrem áreas mais periféricas da cidade, enquanto no centro - área mais valorizada, que compreende o perímetro urbano tombado pelo antigo Serviço do Patrimônio Histórico e Artístico Nacional (SPHAN) ${ }^{5}$ e onde se concentra a maior parte das igrejas barrocas do século XVIII - a preponderância é das imagens.

Uma das justificativas que ouvi em campo a respeito dessa segmentação espacial das formas de representar o Cristo veio do diretor do Museu de Arte Sacra do Pilar, que faz parte e é englobado pela igreja de Nossa Senhora do Pilar, situada na região mais próxima ao centro da cidade. Segundo Carlos:

"[Certas] cidades vizinhas não foram muito felizes em adotar... em adotar figuração [viva] em encenações bíblicas, né? Há casos, por exemplo, de Cristo pregado na cruz com o relógio no braço, essas coisas. Então, Ouro Preto nunca fez isso de colocar um Cristo vivo lá pregado na cruz, não, sempre foi uma imagem de madeira e sempre foi uma... das imagens do século XVIII".

Diferentemente dos locais que apostam em releituras "atualizadas" do drama cristão - como em uma cidade vizinha chamada Congonhas, por exemplo, onde já fizeram uma peça com o Cristo sendo representado por um ator negro -, em Ouro Preto os organizadores da Semana Santa preferem reforçar o caráter "tradicional da festa", que apontei acima. A utilização de imagens barrocas seria, assim, um modo de mobilizar a aura associada a determinadas

5 Atualmente chamado de IPHAN, Instituto do Patrimônio Histórico e Artístico Nacional. Criado nos anos 30, o SPHAN tinha em seu decreto primeiro a definição do que constituía o patrimônio histórico e artístico nacional, a saber: "o conjunto de bens móveis e imóveis existentes no país e cuja conservação seja do interesse público quer por sua vinculação a fatos memoráveis da História do Brasil, quer por seu excepcional valor arqueológico ou etnográfico, bibliográfico ou artístico". Ouro Preto foi uma das primeiras cidades cujas edificações e área urbana foram patrimonializadas pelo Estado brasileiro, tornando-se assim uma referência para a história do patrimônio no país. 
figuras religiosas visando reforçar o caráter "histórico" da Semana Santa em sua versão ouro-pretana, e serviria também para evitar "deslizes" por parte dos atores vivos ou "anacronismos" como o de um Cristo com relógio de pulso.

Há evidentemente outras razões que entram em cena na contraposição que se delineia entre as imagens, de um lado, e os atores humanos, de outro. Deve-se considerar, por exemplo, a larga tradição católica que, em meio a uma festa que mobiliza diversos grupos sociais, coloca em destaque as imagens religiosas, fazendo-as assumir determinados papéis. Em seu estudo sobre as expressões religiosas populares de Portugal, por exemplo, Pierre Sanchis afirmava que "a imagem do Santo de Romaria acede à plenitude de sua presença funcional" justamente no momento de sua exibição em praça pública, quando "ela entra ativamente num jogo eficaz de encenação". É na procissão “[e] através dela que o santo reata e intensifica o contato que sua permanência dentro do santuário tornava simbolicamente mais distante" (Sanchis 1983: 20-21).

Na minha pesquisa (Pereira 2014), abordei em maior detalhe as dinâmicas que envolvem a gradativa preparação ritual e material das efígies que saem em procissão durante a celebração da Semana Santa em Ouro Preto, viabilizando a forma de atividade mencionada por Sanchis. E, de modo complementar, gostaria de destacar aqui o fato de que as efígies do Cristo ganham importância naquele momento não só porque elas lhe dão um corpo material, permitindo que ele seja apresentado às pessoas que participam dos rituais públicos, mas porque elas reforçam - através de sua condição de bens artísticos patrimonializados, como arte sacra e objetos de devoção popular - uma imagem que os ouro-pretanos projetam sobre a sua própria cidade. Como se observa na continuação da fala de Carlos, diretor do museu:

"Ouro Preto tem uma Semana Santa diferenciada, né, se a gente olhar em outros lugares no Brasil. É a própria atmosfera, o lugar, essas ruas tortas, né, esse conjunto. Você tem toda uma ambientação. O barroco trabalhava todos os sentidos humanos, né, e a gente percebe que isso era tão importante que... a gente percebe que essa atmosfera, ela faz parte dessa religiosidade do povo, né?"

Nessa cidade-cenário, considerada propícia para abrigar as dramatizações da Semana Santa, as imagens sacras desempenham um papel de reforço do ideário de sua antiguidade e de sua autenticidade. Algumas delas datam da época de fundação da antiga Vila Rica e seriam portanto "bens culturais" valiosos, que devem ser conservados e "protegidos" em museus como aquele no qual Carlos trabalha. ${ }^{6}$ Quando chega a época de celebrar a Páscoa cristã, esses 
bens passam, não obstante, a ser exibidos também fora das igrejas-museus. As imagens barrocas do século XVIII, em seu duplo registro artístico e religioso, ajudam a reforçar a sacralidade que já estaria contida na representação material de um personagem divino como o Cristo.

Além disso, a valorização de tais ícones como atores rituais se acentua pelas características formais desses artefatos, como me dizia Carlos: "as imagens aqui, elas são vivas, né? Parece que elas são reais. Têm cabelo, têm olho de vidro, 'tão chorando... O Cristo, ele tem... [é] articulado, ele é articulado, ele movimenta. Tem roupa". Falas como essa são frequentes em Ouro Preto e em outras cidades, dentro e fora do país, onde se lida com esse tipo de imagem religiosa (Quites 2006). Entre as várias efígies de Cristo existentes na cidade, aquelas que possuem um tamanho análogo ao de um ser humano adulto e que podem ter seus membros - braços e pernas - manipulados e movimentados de modo a assumir diferentes posturas são as que costumam mobilizar mais as pessoas. Ao acompanhar as interações mantidas antes e durante a festa entre os moradores, devotos ou não, e tais imagens realistas, observei que são produzidas várias analogias entre o corpo humano vivo e o corpo das imagens dos santos, englobando não só as relações mantidas com estes últimos dentro de sua atuação em determinados rituais, mas também sua biografia cultural de modo mais amplo, no sentido que Kopytoff (2008) dá à expressão.

Em sua análise sobre as lógicas que em diferentes sociedades caracterizam a mercantilização das coisas, por um lado, tornando-as "comuns", isto é, comercializáveis, substituíveis, e a sua singularização, por outro, que pode remeter a processos de sacralização e/ou de personalização dos objetos, Kopytoff afirma que seria possível "traçar uma analogia entre a maneira pela qual as sociedades constroem indivíduos e a maneira pela qual constroem coisas" (2008: 120), destacando particularmente os casos intermediários entre os vetores de mercantilização (das "coisas") e de singularização (das "pessoas"). Esses dois termos, entretanto, não seriam fixos. Como relembra o autor, seres humanos já foram comercializados, em contextos de escravidão, e muitas coisas foram e são singularizadas, sendo por isso mesmo frequentemente retiradas do domínio da troca mercantil. Para Kopytoff, as noções do que é um "objeto" e do que é uma "pessoa" variam de acordo com os contextos históricos e culturais. Seria através da reconstituição biográfica de um objeto, portanto, que poderíamos observar a passagem de coisas e pessoas àquilo que as definiria como "comuns", mercantilizáveis, ou o contrário, quando esses objetos ou seres humanos adquirem um estatuto cultural particular, destacando-os de todo o resto.

No caso das imagens religiosas de Ouro Preto, a sua singularização se realiza por pelo menos duas vias complementares. De uma parte, através daquilo que focaliza sua condição de bem artístico patrimonializado, como ficou claro quando conversei com o diretor do Museu do Pilar e ele me disse que o museu 
da igreja serviria como uma "caixa-forte", para proteger aquilo que estava em seu interior. Com isso, tornou-se evidente o caráter valioso e, nessa mesma medida, singular (porque não substituíveis) daqueles objetos ali protegidos. De outra parte, e complementarmente, quando elas são utilizadas num contexto ritual, as imagens têm identificados, pelas pessoas que interagem com elas, uma série de atributos que as definem como semelhantes a um ser humano - como se elas tivessem sido produzidas à sua imagem e semelhança. Uma das interlocutoras com quem interagi em campo, por exemplo, acentuava um dos elementos que aproximariam imagens sacras e pessoas vivas ao me dizer, a respeito das primeiras, que "santo não come, santo não bebe... [mas] em muita igreja o santo é vestido!" Durante minha pesquisa e a partir da bibliografia que analisa esse tipo de artefato artístico-religioso (cf. Webster 1998; Albert-Llorca 1995), pude constatar que tais imagens ultrapassam sua condição de mero "objeto", sendo progressivamente pessoalizadas. ${ }^{7}$ As imagens dos santos têm, além disso, um corpo (fabricado) que, como o de uma pessoa, também demandaria certos cuidados - incluindo, por exemplo, o de evitar que suas "intimidades" fossem exibidas a olhares curiosos. ${ }^{8}$

\section{O REFLEXO DE UMA CENA “CHOCANTE”}

A manipulação das imagens religiosas de Ouro Preto engloba, para além dos técnicos em restauração de arte sacra e dos funcionários do museu onde Carlos trabalha, pessoas que assumem outro tipo de responsabilidade com os santos. ${ }^{9}$ Quando se aproximam os momentos festivos em que as imagens religiosas serão retiradas de seus altares ou vitrines e serão exibidas em áreas públicas da cidade, o trabalho das "zeladoras" - em sua maioria mulheres - ganha maior visibilidade. São elas as responsáveis por preparar as imagens (trocar suas

7 O gradiente de pessoalização pode avançar e gerar diferentes efeitos, como aponta Christian Jr. (1972: 132), por exemplo, que aborda o estabelecimento de um tipo de parentesco entre determinados santos e sua comunidade de devotos: "Mary and other more universal saints $[\ldots]$ have undergone a somewhat revolutionary humanization of their image since the middle ages and are accessible not merely as sources of power to be tapped [...], but also as parents or uncles, to be loved and revered."

8 Ao falar da biografia cultural de um artefato como o que descrevo, pode-se remeter ainda ao próprio contexto de produção das imagens, que já indicam formas de pessoalização que se acumulam ao longo de sua existência. Em seu estudo sobre as imagens sacras utilizadas nas festas sevilhanas do século XVIII, por exemplo, a historiadora de arte Susan Webster (1998: 104-105) afirma que a madeira era considerada pelos artesãos espanhóis de setecentos como uma "matéria quente", pois o material orgânico carregaria suas propriedades mesmo depois de ter sido cortado ou arrancado do solo. A madeira manteria suas qualidades latentes como algo vivo, em contraste com a pedra, o mármore e outros materiais geológicos que seriam vistos como inertes e passivos. Assim, desde suas origens, imagens religiosas como as de Ouro Preto (cuja origem atribui-se a Espanha ou Portugal) poderiam ter reconhecidas certas características que as aproximariam de um ser vivo e expressivo, tal como uma pessoa.

9 A utilização do termo "santo" tem o intuito de seguir a fala nativa, que o aciona de modo substitutivo a "imagem do santo". 
roupas, arrumar os cabelos, limpá-las e, às vezes, perfumá-las) para sua atuação na Semana Santa.

A atribuição do papel de zelador está frequentemente associada às relações de parentesco, amizade e vizinhança. Isso faz com que os pais costumem ser substituídos por seus filhos e filhas na tarefa de cuidar dos santos (incluindo aqueles que durante o ano ficam resguardados dentro de uma igreja-museu), ou que uma zeladora indique a filha de uma amiga para dar continuidade ao trabalho quando aquela, por qualquer razão, precisar se afastar desse posto. No caso de Rita Cota, uma senhora que cuida de um dos Cristos que participa das cerimônias públicas da Semana Santa, o seu trabalho como zeladora é herança de sua mãe. Nascida em Ouro Preto, na mesma casa onde ainda mora, ela é responsável pelo "passo" que fica contíguo à sua residência, localizada na rua Getúlio Vargas. Cada "passo" - do latim passus, que significa sofrimento é uma das capelas que, em seu conjunto, destinam-se a reproduzir o encadeamento de cenas que constituem a via-crúcis, isto é, os episódios que narram a paixão e morte de Cristo. Em Ouro Preto existem atualmente cinco dessas capelas destinadas à exibição de uma imagem particular do Cristo. Todas elas fazem parte do acervo arquitetônico patrimonializado da cidade e definem, tais como marcos geográficos, o percurso das procissões - cortejos estes que sempre têm, durante a Semana Santa, outra imagem do Cristo carregada sobre um andor.

Considerando a centralidade desses ícones para dramatizar o martírio até a crucifixão, e conhecendo as intensas relações de afeto e de devoção que podem ser estabelecidas por algumas zeladoras com "suas" imagens, ${ }^{10}$ foi com bastante surpresa que, em 201 I (já no terceiro ano da pesquisa), ouvi de Rita uma história que eu desconhecia. Foi "uma coisa chocante!", ela me disse referindo-se à imagem que ficava na capela ao lado de sua casa. Tratava-se de uma representação do protagonista da festa sob a iconografia de um Ecce Homo: Jesus com o torso desnudo, as costas cobertas por uma capa vermelha, portando uma coroa de espinhos, o corpo marcado por várias feridas e as mãos atadas por uma corda que está amarrada também ao seu pescoço, como que enforcando-o. O choque citado ocorreu porque durante uma Semana Santa, de anos passados, quando o público (de moradores e turistas que acompanhavam uma procissão) se aproximou desse passo, deparou com um Cristo decapitado. Segundo Rita, tal evento ocorreu nos anos 70 do século passado, mas mesmo depois de tanto tempo, a cena ainda permanece gravada na memória.

Conversávamos a respeito da imagem que fica no interior daquele passo quando ela me interrompeu e disse: "Essa cabeça aí não é dela, não". Sem

10 É comum, ao conversar com as zeladoras, ouvi-las utilizar pronomes possessivos como "minha" Nossa Senhora, ou "meu" santo para se referir a alguma das imagens que fazem parte do acervo de arte sacra da cidade. 


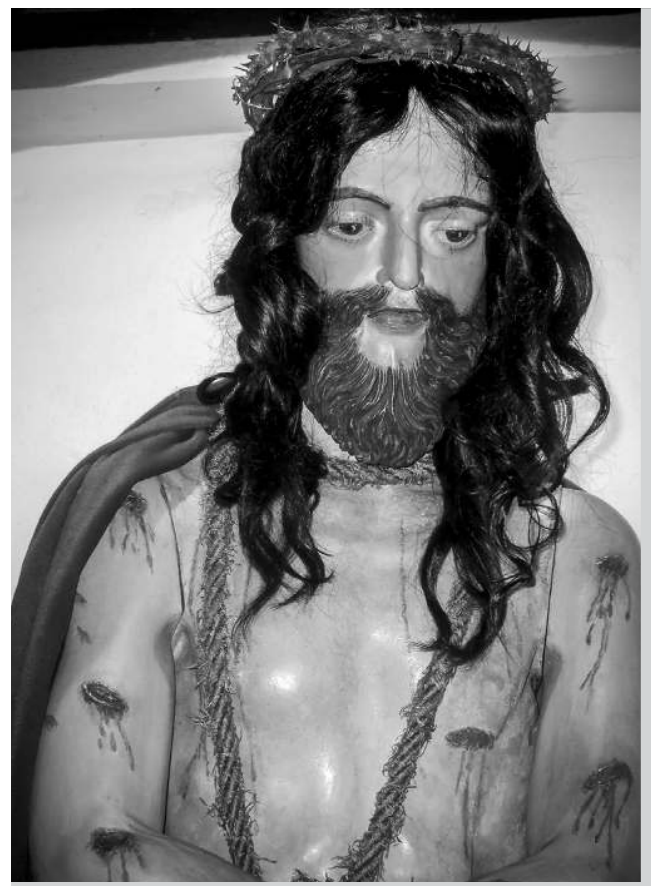

Figura 1 - Ecce Homo, Sexta-feira da Paixão, Ouro Preto, 2013.

Fotografia de Edilson Pereira.

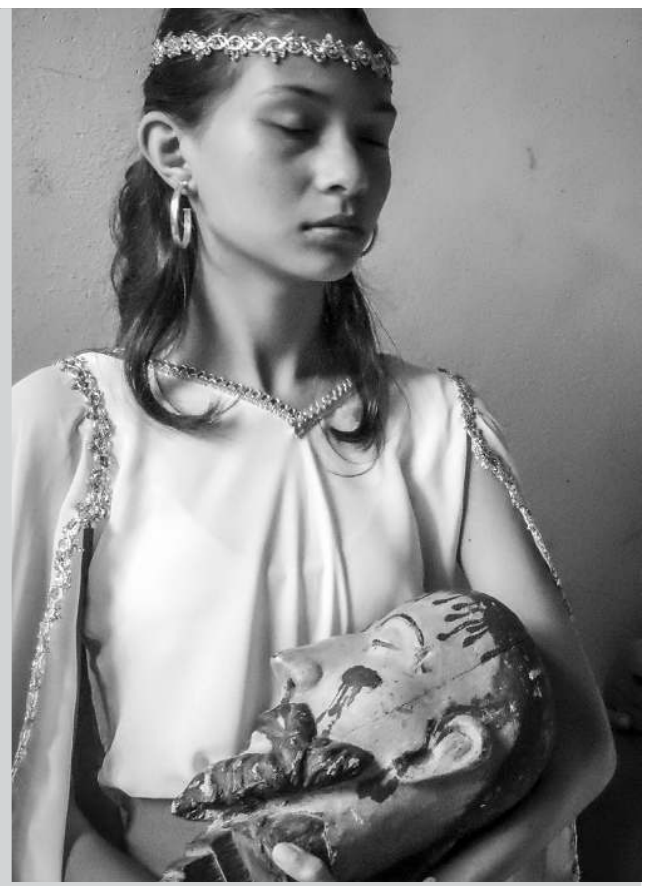

Figura 2 - Figura bíblica, Domingo de Páscoa, Ouro Preto, 2010.

Fotografia de Edilson Pereira.

entender direito, eu perguntei se haviam trocado a cabeça do santo - pois trata-se de uma imagem de madeira, assim como as demais utilizadas na Semana Santa, cujos membros podem ser conectados para formar a integridade do corpo -, e Rita me respondeu: "Não, roubaram! [...] a cabeça foi roubada à noite. Arrombaram a porta [do passo], [e] roubaram apenas a cabeça... a cabeça era encaixada, então desapareceram com ela".

A história do roubo de parte fundamental do corpo do santo, que é também um objeto de arte sacra, pode nos remeter a uma dinâmica mais ampla que envolve a identificação, a patrimonialização e a comercialização (inclusive ilegal) de obras que são classificadas como "bens culturais" - noção importante em um contexto como o observado, de uma cidade patrimonializada e que valoriza tal condição. Mas, para além desse pano de fundo e dos debates específicos que ele envolve, considero que mais interessante do que a situação do roubo em si (ou, melhor dizendo, do relato que o acusa como a causa do evento, embora não houvesse como assegurar se fora efetivamente um ladrão ou um devoto que havia retirado a cabeça da imagem) seja a continuidade da utilização daquele santo para representar a pessoa de Jesus. Quando pensamos numa perspectiva comparativa, considerando outros contextos de religiosidade 
católica, assim como o Norte da Espanha analisado por William Christian Jr. (1972: 80-82), vemos que a reposição/recuperação da imagem de determinado santo - como resultado de sua perda, deterioração ou remoção propositada do altar - está condicionada à atualidade e vigência da devoção mais ampla da qual ela era objeto. ${ }^{11}$ Ou seja, nem toda a imagem de santo é recuperada e volta ao seu respectivo altar ou uso ritual. Observar a posição ocupada (ou abandonada) pelas imagens nos revela, logo, as articulações sociais mais amplas das quais elas fazem parte.

Desse modo, e sabendo que em Ouro Preto existiam outras réplicas do Cristo nas igrejas e museus da cidade, pergunto-me por que, justamente num momento de profundo luto religioso que aciona símbolos rituais para atualizar a paixão cristã, permitiram que se exibisse publicamente o protagonista da festa sem cabeça. Não seria essa uma atitude contraditória? Não se produziria, no meio da Semana Santa, uma forma de blasfêmia, uma transgressão ao respeito que se deduz no contato com as imagens dos santos, ainda mais com um "santo supremo" de quem os demais santos do cristianismo seriam diferentes formas de emulação (Jolles 1976: 41)?

Ora, a imagem em questão não apenas representa um protótipo distante de sua materialidade; ela pode ser interpretada - e frequentemente o é - como um tipo de mediador desse mesmo protótipo divino que, através de uma conjuntura ritual, comunica-se de alguma forma com as pessoas que a tocam, fotografam, emocionam-se e rezam diante e para ela. Ecce Homo, "Eis o Homem" conclamava a efígie com cerca de 1,5 $\mathrm{m}$ de altura posta sobre um altar erigido dentro daquele passo, mas que apesar da posição de destaque não oferecia a possibilidade de interlocução, de se produzir um vínculo de reciprocidade entre aqueles que o olhavam e que esperavam serem vistos de volta. ${ }^{12}$ Um hiato se produz. Naquela ocasião, a imagem exibida era na verdade a de uma ausência radical, obs-cena e contraditória, que colocava em questão (e em hipótese) até mesmo o caráter indubitável de sua identidade. Seria mesmo o corpo do filho

11 Essa mesma dinâmica pode ser identificada em relação à matriz da paróquia do Pilar, onde fica sediado o museu homônimo, cujos altares são dedicados, no presente, a santos distintos do que eram no passado. Essa mudança frequentemente é acompanhada pela alteração das irmandades responsáveis pelo cuidado do altar/imagem de cada santo (Pereira 2014).

12 A existência ou a possibilidade de inferência de algo parecido com "olhos" em diferentes suportes materiais - sejam eles mais ou menos semelhantes a uma cabeça humana ou animal - aparece em vários estudos como sendo um elemento fundamental na atribuição de subjetividade, isto é, de algum grau de humanidade, a diferentes artefatos. A respeito desse tópico, a referência "aos atos do olhar" poderia ser feita a partir do trabalho de diferentes autores, como David Freedberg (1989) e Alfred Gell (1998), mas também Hans Belting (2007) ou Carlo Severi (2011). Apesar das variações existentes entre suas análises, pode-se afirmar que, de um modo geral, os atos do olhar frequentemente são tomados como parte da inferência da capacidade agentiva atribuída aos artefatos - sejam eles quadros, esculturas, efígies, máscaras etc. - ou ao seu reconhecimento como algo "atuante", especialmente quando eles estão associados a contextos rituais. 
de Deus, e não de qualquer santo ou de mártir que pudesse estar imitando-o? Qual rosto ocuparia aquele corpo?

A ausência desse rosto sagrado implica, de uma parte, a perda do "órgão expressivo" por excelência, para reproduzir uma expressão que Simmel (1986: 679) utilizava para diferenciar o rosto do resto do corpo - cujos membros, como mãos, braços e pernas, "fazem" algo ou participam da sua sustentação. O rosto, por sua vez, é o órgão que daria a ver a singularidade de uma pessoa, revelando-a aos seus interlocutores. Ele diria aos demais quem ela é.

Mas quem então exibiria a imagem de um Cristo decapitado a centenas de pessoas que acompanhavam a procissão em plena Semana Santa? E por quê? De acordo com Rita, ninguém menos que padre Simões, o religioso que naquela época era o responsável pela coordenação das atividades da festa. Ao saber que a cabeça daquele Jesus tinha sido roubada, fato que o deixou profundamente consternado, o padre decidiu exibir aquele corpo sem cabeça justamente para gerar espanto, tentando fazer com que os moradores da cidade não ficassem indiferentes ao roubo de parte do acervo de bens culturais que pertencia ao patrimônio local. Na época, instituições como o Museu do Pilar ainda não tinham se consolidado e muitas peças acabavam sendo furtadas por ladrões de arte sacra. Para Rita, essa foi a maneira que o sacerdote encontrou para realizar uma forma de protesto, para gerar algum tipo de espanto que poderia levar à reflexão. De modo parecido com o que propunha Bertolt Brecht (1967) em sua contraposição ao teatro dramático, aristotélico, aquela imagem contraditória - de um Cristo que não se vê por inteiro - deveria mexer não só com os corações, mas também com as mentes dos espectadores da festa. ${ }^{13}$

A (aparentemente boa) intenção do padre, entretanto, não evitou que o susto sentido por diversos moradores se convertesse numa série de reclamações - mais ou menos explícitas, afinal tratava-se de um religioso respeitado na cidade - e, com elas, que sua decisão fosse abandonada para as Semanas Santas seguintes. Era como se a ausência daquela cabeça, daquele rosto sagrado, fizesse penetrar no tempo de luto ritual um tipo de violência diferente da que se esperava ver representada na procissão que reencenava o sacrifício de Cristo. É como se ele já tivesse sofrido demais para redimir os pecados humanos, segundo conta a tradição cristã, e arrancar-lhe a cabeça - ou a cabeça de sua imagem - fosse um excesso.

13 Segundo Brecht (1967: 109) o choque auxilia na produção de um distanciamento que "intervém, não na forma da ausência da emoção, mas na forma de emoções que não precisam corresponder à do personagem representado" no drama teatral. Ou seja, elas (as emoções) não deveriam servir apenas para fazer com que o público se projete sobre a cena e tenha algum conflito pessoal (simbolicamente) resolvido, como num processo catártico. Ele buscava, ao contrário, mobilizar a capacidade crítica e reflexiva dos espectadores frente àquilo que era encenado. A não resolução de um problema e a inclusão de elementos contraditórios eram vistos como algo positivo no teatro brechtiano. 


\section{O PESO DA CABEÇA E SUA DESFIGURAÇÃO}

A cabeça tem um peso fundamental na constituição da humanidade que se reconhece no Cristo, mas também na sacralidade que seria inerente à sua dimensão divina. Inversamente, o vazio de seu rosto coloca em relevo a negatividade que se vislumbra pela ausência desse mesmo teor divino - como se infere a partir da própria história do cristianismo. No contexto medieval, por exemplo, a ocultação dos rostos através de máscaras foi intensamente condenada pela Igreja porque elas poderiam ser utilizadas pelo Demônio, o mestre dos disfarces e da enganação. Por outro lado, a figura de Deus teria uma única face - a de Cristo -, aquela que seria a similitudo legítima e verdadeira (Schmitt 2001: 217). O rosto de Cristo, na tradição cristã, seria sempre aquele que se revela, que se deixa ver como é verdadeiramente.

Abordando problemas teológicos complementares a esse, mas observando-os desde o momento presente, Giorgio Agambem nos lembra também o seguinte:

"Na nossa cultura, a relação rosto/corpo é marcada por uma assimetria fundamental, que [...] corresponde um primado da cabeça, que se manifesta dos modos mais variados, mas que permanece mais ou menos constante em todos os âmbitos, da política (na qual o titular do poder é chamado de capo [em português: cabeça, chefe]) à religião (a metáfora cefálica de Cristo em Paulo), da arte (na qual se pode representar a cabeça sem corpo - o retrato -, mas não - como é evidente no 'nu' - o corpo sem cabeça) à vida cotidiana, na qual o rosto é por excelência o lugar da expressão" (Agambem 2014: 126).

A exibição ritual de Cristo sem cabeça coloca em evidência um tipo de excesso - de ausência - que as pessoas não estavam preparadas para ver, como bem imaginava o sacerdote ouro-pretano, mas que por isso mesmo fez com que tal ato contivesse um caráter fundamentalmente ambivalente. Pois se, por um lado, a iniciativa foi bem sucedida no sentido de que pelo choque produziu-se memória, quase como num trauma - como me mostrava Rita ao falar desse episódio com detalhes -, por outro, o espanto era provocado porque, inevitavelmente, aquela exposição estava sendo passível de ser compreendida como um ato blasfemo, transgressor.

Para pensar essa situação eminentemente ambígua, considero úteis as observações de autores como Michel Leiris e Georges Bataille, para quem as relações entre sagrado e profano não eram necessariamente opositivas e de autoexclusão. ${ }^{14}$ Ao invés disso, eles pensavam o caráter ambivalente do sagrado, como 
sintetizou Bataille: "o sagrado designa ao mesmo tempo duas coisas opostas. [...] o terror, que intimida, e a atração, que comanda o respeito fascinado" (1987: 63-64), ou ainda, "o sagrado é precisamente comparável à chama que destrói a madeira ao consumi-la. Ele é este contrário de uma coisa, o incêndio ilimitado, que se propaga, irradia calor e luz, inflama e cega..." (1990: 44). Como autores relacionados - ainda que de modos variados - com certo conjunto de ideias que marcou o surrealismo europeu, eles também se colocaram a repensar as relações mantidas (na arte e fora dela) com o corpo humano, que estaria, ainda, aprisionado na concepção unitária cristã que toma a natureza terrena de Jesus como modelo referencial para os homens. ${ }^{15} \mathrm{Na}$ contramão dessa perspectiva, esses intelectuais se apoiavam na ideia de fragmentação e decomposição da figura humana. Através de suas obras literárias e visuais, eles faziam intervir no corpo humano forças e objetos improváveis, ao mesmo tempo em que traçavam outras aproximações com o domínio do não humano, do bestial. A produção da revista Acéphale ilustra de modo bastante claro a valorização dessa desfiguração transgressora. ${ }^{16}$

Falando sobre esse conjunto de ideias, Eliane Robert de Moraes aponta que na figura do "homem sem cabeça" deve ser reconhecida

“a imagem do 'ser inacabado' que remete $[\ldots]$ a uma das mais frequentes definições de monstro, presente tanto em textos da Antiguidade quanto no Renascimento. [...] Sem dúvida, a imagem de um homem sem cabeça expressa, por excelência, a ideia do ser privado ou desprovido de alguma capacidade ou órgão indispensáveis na qualificação do humano e, enquanto tal, constitui-se uma das principais matrizes dos 'desvios da natureza'" (Moraes 2012: 184-185).

sagrado e profano. Entre elas, provavelmente, a clássica análise de Durkheim que ressaltava a existência de uma "dualidade radical" (1996: 26) entre tais noções, tomadas como opostas e correlacionadas entre si. De sua parte, Durkheim também mencionava uma ambiguidade do sagrado, mas no sentido em que haveria um sagrado puro (fasto) e um impuro (nefasto), como duas forças que provocariam o bem ou o mal (cf. 1996: 425 e segs.) e que eram vistas, ainda, como totalmente distintas do profano. Em contrapartida, a reflexão apresentada, por exemplo, por Leiris em "Le sacré dans la vie quotidienne", observa como o sagrado pode irradiar de objetos, brincadeiras e experiências aparentemente banais, inclusive no ambiente doméstico e familiar - ampliando, dessa forma, a análise para além do chamado "sagrado oficial" que ele reconhecia na política, na religião e na moral, e que seria distinto de tudo considerado ordinário e profano (Leiris 1979 [1938]).

15 Em sua análise sobre "a noção de pessoa", também Marcel Mauss (2003: 392) apontava que "nossa própria noção de pessoa humana é ainda fundamentalmente a noção cristã", esta baseada na ideia de singularidade e de unidade do "eu". A pessoa é vista, logo, como um ser uno - tal como a própria Igreja e Deus o seriam.

16 Com o subtítulo composto pelas palavras "Religião, Sociologia, Filosofia", a revista teve seu primeiro número publicado em 1936, sob a responsabilidade de Georges Bataille, Pierre Klossowski e André Masson. 
A profanação do corpo criado à imagem e semelhança de Deus produz um tipo de deslocamento simbólico que gera, como resposta, o espanto diante da inumanidade/monstruosidade de um corpo sem cabeça - ainda mais se ele estiver sobre um altar, dentro de uma capela aberta à vista de todos os que passam diante dela. Mas isso não é tudo, como afirma Moraes ainda a respeito das ideias de Bataille:

"Contudo essa mutilação não é apenas negativa [...]. A ausência de cabeça não significa portanto ausência de vida, e a ferida da decapitação abre novas possibilidades de sentido para a existência humana. Ademais, o corpo vivo e potente do decapitado atesta que a cabeça é apenas um de seus limites orgânicos. Restam as outras extremidades. Ou, simplesmente, o resto do homem" (Moraes 2012: 187).

O caráter ambivalente de um corpo santo decapitado se expressa aí também; objeto de repulsa e alvo de interesse, imagem inesquecível para aqueles que enxergavam a subjetividade que poderia ser inferida da imagem de um santo. A "ausência sagrada do rosto", para parafrasear outro comentador de Bataille (Didi-Huberman 1998), pode nos fazer atentar não só àquilo que falta, mas também a algo que se revela no interior mesmo dessa (suposta) ausência.

Ao meu ver, a história que acompanhamos em Ouro Preto pode ser entendida como uma transgressão movida por um religioso que rompe com certo interdito - aquele que proíbe a manipulação considerada desrespeitosa para com os santos e suas imagens, ainda mais no momento em que eles estão em destaque, quando se realiza uma festa em sua homenagem. Ao transgredir essa fronteira, entretanto, o próprio ato transgressor produziu, como efeito, um reforço da validade e da demanda pelo "respeito" àquele corpo de Cristo. Lidamos, pois, com uma atitude que colocou em ação aquilo que Michael Taussig (1997) chama de "poder do negativo", como uma característica dos atos transgressores - sejam eles intencionais ou não. Inspirado em autores como Walter Benjamin e Bataille, Taussig afirma que a relação mantida entre sagrado e profano opera numa lógica de interação contínua que se aproxima mais da ideia de um circuito - que pode entrar em curto-circuito, aliás, como na situação de choque dos devotos diante de um santo sem cabeça no meio da procissão - do que de uma oposição radical entre os termos.

Além disso, para o autor, o corpo e a imagem não seriam apenas símbolos ou sintomas da transgressão no domínio religioso, mas antes o seu próprio veículo de realização. Segundo Taussig: "Death and dismemberment return us to the human body as a privileged theatre of sacred activity in a way that makes it hard to avoid the topics of automutilation, of the killing of the god, and of the god killing himself" (1997: 360). Como vemos, as formas de transgressão que ocorrem dentro do cristianismo, onde o filho de Deus tornado homem 
é sacrificado por seu próprio pai, aparecem como particularmente úteis para pensarmos os (curtos-) circuitos entre sagrado e profano.

Exemplo privilegiado de retroalimentação mantida entre tais polos estaria nos chamados "segredos públicos", segredos que não são necessariamente desconhecidos, mas que ao serem alvo de uma "revelação" transgressora não perderiam a sua força, não se anulariam. Ao contrário: a própria intenção de desvelamento poderia colaborar na sua sacralização, no reforço de seu mistério e na produção do make-believe de que pode haver, ainda, algum outro segredo guardado (Taussig 1997).

Se voltarmos nossa atenção à situação ouro-pretana, veremos que o que o padre Simões fazia, no mesmo ato de "protestar" contra o roubo de arte sacra e tentar mobilizar a população para aquele problema (ou seja, para defender aquele artefato), era revelar o segredo público de que aquele Cristo era uma imagem de madeira considerada bem cultural. Dentro da capela que serve de frame para o Ecce Homo (indicando a sacralidade que lhe deve ser imputada e, ao mesmo tempo, servindo para que ele fosse destacado de todo o entorno, que está fora daquele passo), a exposição do corpo decapitado, nem vivo, nem morto, colocava em primeiro plano - e acima da atuação ritual prevista, como mais um ícone que colabora no fluxo de imagens que recontam a via-crúcis a condição de artefato artístico da imagem, como "bem material" fabricado por mãos humanas, estética e historicamente localizáveis. Mãos profanas, portanto, demasiadamente humanas para um momento liminar como o da Sexta-Feira da Paixão. Aquele ato profanador - não só do objeto em si, mas da relação mantida entre os ícones religiosos e o corpo dos fiéis, que se espantavam ao olhar para ele pois viam que qualquer possibilidade de "mistério" por trás dele havia sido reduzida a um objeto despedaçado, uma cabeça roubada - produziu como resposta uma intensificação da sacralidade do Ecce Homo, como se infere do abandono da estratégia de choque mantida pelo sacerdote e, posteriormente, na busca de uma nova cabeça para Jesus.

Conforme disse Rita, finalizando a história que me contava:

"Você sabe que ele [o padre] era polêmico, que ele gostava de causar impacto mesmo, né? P’ra ver se sensibilizava quem roubou. Mas não apareceu. Aí, depois... Angelo Oswaldo, o prefeito atual, quando ele era prefeito da outra vez, ele indo à igreja de S. Francisco de Assis, tem um malão lá com algumas peças. E ele viu uma cabeça de apóstolo [e], como ele conhece tudo, né, ele conhece todas as peças de arte aqui de Ouro Preto, ele falou assim: 'Eu acho que essa cabeça serve lá no passo'. Trouxe pra cá. Não é bonita como a de antigamente, [mas] encaixou maravilhosamente".

Dentro de um acervo de peças de arte sacra, reunidas indiferentemente entre si, o então prefeito fez uma busca de cabeças naquele repertório de máscaras 
possíveis. Mas qual seria aquela que poderia se "encaixar maravilhosamente", como dizia a zeladora, isto é, que pudesse imitá-lo tão bem a ponto de se fazer passar pelo próprio Cristo? Curiosamente, é a cabeça de um apóstolo, de um seguidor, que assume o corpo daquele que era o seu mestre. $\mathrm{O}$ apóstolo que mimetizava se torna agora a imagem mesma que ele copiava.

Nessa substituição de cabeças, observamos, de modo análogo ao que descreve Taussig (1999), que o defacement opera a partir de uma negação, mas não se realiza como uma mera subtração. Na verdade, a desfiguração atua mais como uma obliteração, um tipo de esfacelamento das margens do jogo que definia o que era explícito/oculto até o momento do ato transgressor, e que será reorientado depois da sua intervenção. Assim, ao ser recomposta a "face" em questão, o defacement "ativa a sacralidade que é atribuída a essas coisas [materiais]; fechando o circuito que realiza o vínculo entre uma imagem e o que ela representa" (Giumbelli 2014: 146). Para cada cabeça perdida, outra poderia ser encontrada para the tomar o lugar e tornar presente, sob certas condições, a sua pessoa.

\section{O OUTRO (DO) CRISTO}

Ao refletir sobre essa dinâmica de trocas da cabeça dos santos, como num jogo de máscaras e de suas personas e identidades públicas, proponho pensar ainda um último exemplo que, ao meu ver, pode ser relacionado ao tipo de movimentação simbólica que acompanhamos até aqui. Trata-se da relação entre a face de Cristo e a de outra figura que conta com um culto público no centro patrimonializado de Ouro Preto. Sua existência histórica coincide com o tempo de origem das imagens barrocas do século XVIII e sua biografia é alvo, igualmente, de especulações que envolvem as ideias de martírio, sacrifício e consagração. Passemos então da materialidade da imagem do Ecce Homo, com seu corpo flagelado, as mãos atadas e o pescoço envolto por uma corda, à figura de Tiradentes, famoso cidadão ouro-pretano associado à história nacional - sobretudo em sua versão republicana.

Conforme se ensina nas aulas de história do Brasil, Joaquim José da Silva Xavier foi um dos sujeitos envolvidos num movimento relativamente organizado que ficou conhecido como a Inconfidência Mineira. No cenário do Brasil colônia, cuja extração de minerais (tal como aquele que dá nome a Ouro Preto) constituía-se ainda como importante atividade econômica, as relações entre mineradores de origens diversas, por um lado, e funcionários da coroa portuguesa, responsáveis pela cobrança de impostos como o "quinto", ${ }_{17}^{17}$ por outro, eram continuamente conflituosas - e percebidas, em versões da história que

17 O quinto do ouro correspondia a um imposto de $20 \%$ do metal extraído na região e cobrado pela Metrópole. 
recontam a vida de Tiradentes, como profundamente injustas. Diante desse quadro, o militar de baixa patente (um alferes) e outros sujeitos que tinham certas posses defendiam que os impostos, considerados abusivos, não fossem pagos; que as riquezas extraídas do solo das Gerais permanecessem nas mãos daqueles que ali viviam, contrapondo-se à exploração mantida pelo reino do outro lado do Atlântico. Por parte da coroa portuguesa, essas ideias foram recebidas como uma conspiração, um plano de deposição política, uma blasfêmia ao poder colonial. ${ }^{18}$ Em resposta a isso, e seguindo as ordens D. Maria, a Louca, os inconfidentes foram alvo de um processo chamado de "devassa", que cuidava de investigar todos os detalhes e os envolvidos na difusão de ideias de (suposta) independência e que tratava de definir as respectivas punições aos acusados. Entre aqueles que foram alvo da repressão portuguesa, apenas Tiradentes - visto como o cabeça do grupo - foi condenado à morte em praça pública, fato que ocorreu em 21 de abril de 1792, no Rio de Janeiro. Os demais presos políticos foram em sua maioria condenados ao degredo na África.

Quanto maior a violência do sacrifício, maior o sentimento de sacralidade que ele envolve, dizia Bataille (1987). E assim como vimos que o defacement do Ecce Homo se completava pela substituição da ausência através da colocação de nova cabeça no santo, nos cabe questionar qual seria a imagem que pôde assumir o rosto desse sujeito que foi enforcado e depois teve o seu corpo esquartejado, os membros salgados para que durassem mais e pudessem ser exibidos por mais tempo, servindo assim de exemplo do perigo de se desafiar o poder da coroa portuguesa.

Do corpo desse homem - cujos descendentes e parentes mais próximos foram obrigados a abandonar o sobrenome, para apagar a identidade daquela linhagem - restou, todavia, a cabeça que, segundo reza a lenda histórica, foi enviada de volta a Ouro Preto para ser exibida aos seus conterrâneos. Essa cabeça deveria servir como imagem (sacra) da força colonial e da fraqueza daquele que ameaçou tal poder. Como sublinha Moraes (2012: 17): "Gesto último do ritual da execução, a exibição do rosto do decapitado pelo carrasco anunciava o triunfo do corpo político sobre seus traidores, culminando o espetáculo com a apresentação do 'verdadeiro retrato do monstro' ". Ao falar da guilhotina usada no contexto revolucionário francês, que separava o corpo da cabeça, a autora refere-se a essa máquina de decapitação ritual como a primeira máquina de tirar retratos - que focam apenas uma parte da pessoa, justamente

18 Como se constata na declaração feita em 1798 pelo Visconde de Barbacena, enviado de Portugal à Vila Rica: "A Mão do Omnipotente que regula o justo e feliz Governo de S. Mag. de acaba de defender este paiz, se não da sua ruina ou perdição total, ao menos de hum gravissimo estrago irreparavel por muitos annos, e tem encaminhado as minhas diligencias de tal forma, que tenho a gloria de poder ao mesmo tempo dar parte a V. ${ }^{a}$ Ex. ${ }^{a}$, do grande perigo com que lhe ameaçou o Sacrilego attrevimento de alguns perversos Homens, e da completa vitoria com que se acha rebatido, e descoberto pela maior parte o infame sistema da sua maldade" (apud Maxwell 1978: 168). 
aquela que permitiria (graças ao valor dado ao rosto) identificá-la, distinguindo-a de todas as outras.

Mas se nos lembrarmos que "matar, na verdade, nem sempre tem significado literal", como nos avisava Bataille (1990: 39), Tiradentes pode ganhar nova vida através de uma outra feição que ele passou a assumir após seu sacrifício. Apesar, ou melhor, por causa mesmo de sua decomposição física realizada com extrema violência, Tiradentes foi reavivado através de diferentes histórias que serviam para que grupos variados se apropriassem da sua figura e a envolvessem com máscaras particulares, dando-lhe feições que refletiam seus próprios valores. Num processo que foi sendo renovado em diferentes épocas, podemos ver que a consagração de Tiradentes se iniciou ainda no contexto final da monarquia no Brasil, passou pela instauração do Estado Novo e atravessou o último século até chegar aos dias atuais. E apesar das evidentes diferenças existentes entre tais momentos históricos, pode-se observar a continuidade de uma projeção que acaba transformando o Tiradentes em uma mimese do Cristo.

Ao falar sobre o primeiro desses momentos, o historiador José Murilo de Carvalho (1990) comenta a contraposição que se formou no século XIX entre monarquistas e republicanos - estes últimos rebatendo a imagem de Tiradentes à de D. Pedro I. Os antimonarquistas tomavam Tiradentes como um "herói que se sacrificava por uma ideia" (Carvalho 1990: 60), uma espécie de mártir. Depois de proclamada a República, em 1889, o culto a Tiradentes intensificou-se de tal modo que as celebrações cívicas em homenagem ao líder político brasileiro se confundiam com um culto religioso, como aponta Carvalho: "O desfile que passou a fazer parte das comemorações do 21 de abril [dia da morte de Tiradentes] lembrava a procissão do enterro de sexta-feira santa. As analogias apareceram já no primeiro desfile realizado em 1890 [no Rio de Janeiro]" (1990: 64). Formava-se, dessa forma, a imagem de um "Cristo cívico" (1990: 67).

Algumas décadas depois, já no contexto dos anos 1930, na mesma época em que Ouro Preto seria elevada à categoria de "Cidade Patrimônio Nacional" (uma passagem fundamental para sua posterior configuração como destino turístico), o então presidente Getúlio Vargas cedeu aos apelos de intelectuais e políticos mineiros e assinou um decreto que autorizava a repatriação dos restos mortais dos inconfidentes falecidos no degredo. Para recebê-los, o estadista ordenou que fosse feita uma reforma na antiga Casa da Câmara e cadeia para que ela se tornasse o Museu da Inconfidência - um amplo edifício que fica bem no centro de Ouro Preto, justamente no local onde teria sido exposta a cabeça de Tiradentes nos idos do século XVIII.

O mesmo presidente que dá nome à rua onde fica a capela do Ecce Homo ouro-pretano foi, assim, um dos responsáveis pelo acionamento da busca pela materialidade dos restos corporais daqueles que haveriam sido injustamente 
punidos no passado. Nessa procura revela-se o caráter ritual de recuperação e exibição de algo que se havia perdido, de tentativa de supressão de um (recém-criado) vazio. Ou ainda, como bem aponta a indagação de Bruno Latour (2008: 115): "Não são os museus os templos nos quais sacrifícios são feitos para se pedir desculpas por tanta destruição, como se quiséssemos de repente parar de destruir e estivéssemos começando o culto indefinido de conservar, proteger, reparar?" A instituição do Museu da Inconfidência pode ser vista assim como uma forma de continuação do movimento que tenta redimir os excessos implicados àqueles corpos - cada vez mais sacralizados. Além disso, e se nos lembrarmos das palavras do diretor do museu de arte sacra citado anteriormente, Carlos, espaços como aquele servem como uma "caixa-forte", que tanto protege quanto permite que as peças de seu acervo continuem presentes, isto é, sendo expostas - ao contrário do que ocorreu com aquela cabeça do Cristo, que desapareceu.

Se, como dizia Marx, a história só se repete como tragédia ou como farsa, ${ }^{19}$ nos dois casos parece-me que as aproximações entre Cristo e Tiradentes se difundem de modo a reforçar a criatividade envolvida na crucifixão (política ou religiosa), entendida aqui não como uma mentira, mas como uma criação, uma dramatização tal como o é como uma tragédia teatral. Digo isso porque, de sua parte, a cabeça de Tiradentes, levada à Vila Rica e exposta em seu pátio central de modo análogo aos rituais de crueldade que Foucault (2009) analisa no início de Vigiar e Punir, também teve um destino obscuro como a do Ecce Homo. Ela desapareceu. Numa cidade que tem no culto à história e ao passado um importante valor compartilhado entre seus habitantes, a materialidade que permitiria identificar esse santo político em sua singularidade, o índice corporal que permitiria remeter à sua existência histórica concreta aparece apenas como ausência que tenta ser suprimida pela reposição de outras faces - dentre as quais a de Cristo parece ser a mais potente.

A aproximação entre as duas figuras se realiza, todavia, ainda nos dias mais próximos de nosso tempo. A imagem do mártir político continua sendo manipulada de modo a não apenas se constatar a sua desfiguração passada, mas a dar vazão a uma atividade contrária, que visaria preencher de alguma forma o "espaço vazio" criado naquele corpo completamente aniquilado e - na mesma medida - santificado. Em seu estudo sobre as representações de Tiradentes na imprensa brasileira no século XX, por exemplo, a historiadora Thais de Lima e Fonseca (2002) nos mostra como aquela cristianização da figura destacada por Murilo de Carvalho, no século XIX, segue atualizada nos períodos históricos

19 Como se lê no parágrafo de abertura de O 18 de Brumário de Louis Bonaparte: "Hegel observa em uma de suas obras que todos os fatos e personagens de grande importância na história do mundo ocorrem, por assim dizer, duas vezes. E esqueceu-se de acrescentar: a primeira vez como tragédia, a segunda como farsa" (Marx 1851-1852). 
seguintes. Ela recupera, por exemplo, uma nota publicada no jornal O Estado de Minas, em 2000, onde a aproximação entre Cristo e Tiradentes ganha destaque pela coincidência das datas de celebração de seus sacrifícios:

"Hoje o coração do povo brasileiro vivencia a emoção de dupla cerimônia: uma religiosa e outra cívica, quando celebra-se a Sexta-feira da Paixão e o Dia de Tiradentes [...]. Coincidentemente, Cristo e Tiradentes morreram por causas nobres, visando o bem-estar do homem. Cristo por pregar a verdade, o amor, a paz, a igualdade, na tentativa de libertar o homem do pecado. Tiradentes, por pregar e lutar pela tão sonhada liberdade do povo brasileiro, explorado e massacrado pela Coroa portuguesa, e por querer fazer deste País uma verdadeira nação. Um na cruz, outro na forca. [...] É intrigante. Uma pergunta cuja resposta nunca convence. Por que as pessoas de bem, honestas e dedicadas às causas alheias pagam tão alto por seus nobres gestos?" (apud Fonseca 2002).

Junto ao sentimento reavivado por ocasião dos feriados coincidentes, conforme expresso nessa nota, chama a atenção também a continuidade daquela prática de remissão do pecado colonial contra os inconfidentes. Tanto o sentimento quanto a prática relacionada se vinculam, ainda, com um ritual político instituído desde os anos 1950 pelo então governador de Minas Gerais, Juscelino Kubitschek. Foi a partir do seu governo que a capital mineira passou a ser simbolicamente transferida de Belo Horizonte (a atual capital administrativa) para a histórica Ouro Preto em cada dia 21 de abril. Anualmente, diferentes figuras públicas são condecoradas por líderes políticos com a Medalha da Inconfidência, uma honraria concedida até hoje pelo Estado brasileiro.

Em 2011 , já sob o governo de Dilma Rousseff, a presidenta viajou para Ouro Preto para seguir o ritual estabelecido e condecorou as pessoas que teriam se destacado no país ao longo do último ano. A cerimônia naquele 21 de abril teve, porém, um momento de particular destaque: quando se fez menção às novas urnas com os restos mortais dos inconfidentes que finalmente estavam sendo recebidas na cidade. Tratava-se dos restos de três outros degredados que haviam sido recuperados ainda no governo de Getúlio, mas que não tinham sido identificados até então - tarefa agora possível graças a novas tecnologias de pesquisa. ${ }^{20} \mathrm{O}$ percurso temporal entre o momento de retorno das ossadas ao Brasil e, após décadas, a sua identificação e transporte para o Museu da Inconfidência chegou a ser tratado como um tipo de peregrinação, como ilustra um

20 Para mais detalhes a respeito da cerimônia, cf. a notícia "Restos mortais de inconfidentes", assinada por Ezequiel Fagundes e publicada no Correio Braziliense em 22/04/201 l, disponível em < http://www2. senado.leg.br/bdsf/bitstream/handle/id/49469/complemento_l.htm? sequence $=2>$ (última consulta em maio de 2016). 
jornalista do $O$ Estado de $S$. Paulo, remontando mais uma vez as figuras políticas às noções do domínio religioso:

"Depois de uma peregrinação por instituições públicas, os restos mortais foram encaminhados em 1994 para a unidade da Unicamp, em Piracicaba, onde permaneceram os últimos 17 anos e foram submetidos a um processo de identificação [...]. O prefeito de Ouro Preto, Ângelo Oswaldo, lembra que as três ossadas chegaram ao Brasil 'misturadas' [...]: 'Eles ficaram durante anos dentro de uma urna, nos arquivos do Itamaraty, no Rio de Janeiro'". ${ }^{21}$

Lembro que o prefeito citado, Angelo Oswaldo, é o mesmo que aparecera anteriormente na fala de Rita a respeito do encontro de uma nova cabeça para o Ecce Homo; foi ele que encontrou dentro de uma grande mala cheia de outras peças de arte sacra, ou melhor, de outros restos corporais dos santos, todos eles misturados, a que se identificava com o Cristo. Além disso, a própria conversa que tive com Rita a respeito da decapitação daquela imagem, como possível resultado de um roubo, aconteceu na mesma época em que as ossadas citadas acima eram levadas para Ouro Preto. E, para completar as aproximações não planejadas entre certos eventos de que fui me dando conta somente durante o processo de escrita deste texto, naquele mesmo 2011 , a data do 21 de abril caía numa Quinta-Feira Santa, véspera do dia em que se celebra a morte de Cristo. Os dois martírios se somavam mais uma vez no calendário festivo da cidade.

Foi então no mesmo contexto ritual, em que referências simbólicas se cruzavam inclusive de modo material - pois a praça Tiradentes também é um lugar onde se realizam atividades decisivas das procissões da Semana Santa, que têm de disputar espaço com os palanques erigidos para destacar as figuras políticas -, que a chegada daquelas ossadas deixava em destaque a $14 .{ }^{a}$ lápide dos inconfidentes que, diferentemente das outras 13 ocupadas, permanece sem nome, vazia. No interior do Museu da Inconfidência, ela marca a ausência daqueles que não foram recuperados; a ausência dos desaparecidos, incluindo, entre eles, Tiradentes.

Mas ocorre que nessa mesma conjuntura festiva - e para voltarmos às procissões que nos serviram de ponto de partida -, num contexto em que uma centena de personagens bíblicos passam a ser representados por moradores da cidade como parte da encenação que revisita várias passagens até culminar nos eventos que marcam a paixão e morte de Cristo, eis que ouço aqui e acolá alguns sussurros sobre Tiradentes. Nas margens das procissões dessa época, eu

21 Da notícia "Minas homenageia três inconfidentes", assinada por Eduardo Kattah e publicada n’O Estado de S. Paulo, disponível em < http://politica.estadao.com.br/noticias/geral,minas-homenageia -tres-inconfidentes,706914> (última consulta em maio de 2016). 
notava que certas pessoas se perguntavam, de modo jocoso, se determinada cabeça levada em meio ao cortejo da Semana Santa seria, enfim, aquela desaparecida séculos atrás. Por intermédio do ritual e da dramatização que ele coloca em evidência, trazendo diferentes representações sociais à tona e destacando-as daquelas que regem a vida do dia-a-dia, a cabeça que era vista nas mãos de figuras bíblicas como Judite (figura do Antigo Testamento que degola um militar que queria invadir a terra dos israelitas) ou da escrava de Herodes (rei que satisfez o desejo de Salomé, filha de sua esposa, que queria ter a cabeça de João Batista numa bandeja, de presente) era pensada como possível substituta daquela do mártir ouro-pretano. Assim, entre risos discretos, essas pessoas faziam Tiradentes passar de Cristo político a personagem improvável das escrituras bíblicas.

Outra vez assistimos à associação entre a perda da unidade do corpo provocada por um ato violento, sacrificial, e a sua recomposição sob uma forma outra, sendo não só objeto de desfiguração, mas também de transfiguração. Entre as cabeças de Cristo e de Tiradentes observa-se um jogo de máscaras, de suas personas trágicas e heroicas. Ao invés de apresentarem-se como pessoas singulares e insubstituíveis - numa visão compatível com nossa concepção moderna de indivíduo, compreendido como ser único -, eles se apresentam mais próximos da ambiguidade característica da persona romana, conforme descrita por Mauss (2003: 389). Na antiguidade, a persona, o "eu", dizia respeito simultaneamente à representação de um personagem teatral, que pode ser continuamente reencenado, e à "verdadeira natureza do indivíduo", que remete a um ser de direito, com um nome e uma história particular. No caso que acompanhamos, uma macronarrativa dramática se vincula a uma trajetória individual, representada sob uma forma trágica, que acaba por afetar o contexto de atualização da primeira. Elas contaminam-se mutuamente.

\section{CONSIDERAÇÕES FINAIS}

Diante de figuras refletidas entre si como imagens em um espelho, minha aposta de leitura se realiza sob a inspiração do procedimento que focaliza as potencialidades do pensamento analógico - fundamental para os autores e artistas vinculados ao surrealismo, que se ocupavam não apenas de "estabelecer correspondências ao comparar os diversos elementos do universo, mas sim de inventá-las" (Moraes 2012: 41). Através deste exercício, aqui baseado em dados etnográficos e na bibliografia comentada, busco abrir uma outra frente de entendimento da representação de personagens sagrados, religiosos e/ou políticos, levando em consideração uma dinâmica de contínua produção de mimese e de alteridade entre eles, evidenciando a fabricação de similitudes e de certas destruições (materiais) ao longo do tempo de suas existências. Em suma, transformando-os. 
Ao compreendê-los como protagonistas de situações que colidem e se reforçam dentro do cenário de uma cidade encantada pelos efeitos da memória e de suas histórias, nós avançamos no conhecimento sobre as formas de pensamento e de expressão que delineiam o imaginário local sobre tais figuras e sobre parte importante de seu próprio passado. Um passado, como nos alertava Benjamin (1987: 224), que "só se deixa fixar, como imagem que lampeja irreversivelmente, no momento em que é reconhecido". No ato de observação dessas imagens, interessa menos aquilo que elas já teriam em si mesmas, a priori, e mais aquilo de novo que conseguimos - ou que elas nos permitem - enxergar.

\section{BIBLIOGRAFIA}

AGAMBEM, Giorgio, 2014, Nudez. Belo Horizonte, Autêntica Editora.

ALBERT-LLORCA, Marlène, 1995, "La Vierge mise à nu par ses chambrières", CLIO: Histoire, femmes et sociétés, 2, disponível em < http://clio.revues.org/494> (última consulta em maio de 2016).

BATAILlE, Georges, 1987, O Erotismo. Porto Alegre, L\&PM Editores.

BATAILlE, Georges, 1990, Teoria da Religião. São Paulo, Ática.

BELTING, Hans, 2007, La vraie image: Croire aux images? Paris, Gallimard.

BENJAMIN, Walter, 1987, Obras Escolhidas, vol. I: Magia e Técnica, Arte e Política. São Paulo, Brasiliense.

BRECHT, Bertold, 1967, Teatro Dialético: Ensaios. Rio de Janeiro, Civilização Brasileira.

CARVALHO, José Murilo de, 1990, “Tiradentes: um herói para a República”, em J. Murilo de Carvalho, A Formação das Almas: O Imaginário da República no Brasil. São Paulo, Companhia das Letras, 55-74.

CHRISTIAN JR., William A., 1972, Person and God in a Spanish Valley. Nova Iorque, Seminar Press.

DIDI-HUBERMAN, Georges, 1998, "O rosto e a terra: onde começa o retrato, onde se ausenta o rosto", Porto Arte, 16: 61-82.

DURKHEIM, Émile, 1996, As Formas Elementares da Vida Religiosa: O Sistema Totêmico na Austrália. São Paulo, Martins Fontes.

FONSECA, Thais Nivia de Lima e, 2002, "A Inconfidência Mineira e Tiradentes vistos pela imprensa: a vitalização dos mitos (1930-1960)", Revista Brasileira de História, 22 (44): 439-462.

FOUCAUlt, Michel, 2009, Vigiar e Punir: Nascimento da Prisão. Petrópolis, Vozes.

FREEDBERG, David, 1989, The Power of Images: Studies in the History and Theory of Response.

Chicago, The University of Chicago Press.

GELL, Alfred, 1998, Art and Agency: An Anthropological Theory. Oxford, Clarendon Press. 
GIUMBELli, Emerson, 2014, Símbolos Religiosos em Controvérsias Públicas. São Paulo, Terceiro Nome.

JOLLES, André, 1976, “A legenda”, em A. Jolles, Formas Simples. São Paulo, Cultrix, 30-59. KOPYTOFF, Igor, 2008, "A biografia cultural das coisas: a mercantilização como processo", em A. Appadurai (org.), A Vida Social das Coisas. Niterói, EdUfF, 89-121.

LATOUR, Bruno, 2008, "O que é iconoclash? Ou, há um mundo além das guerras de imagem?”, Horizontes Antropológicos, 14 (29): 111 1-150.

LEIRIS, Michel, 1979 [1938], "Le sacré dans la vie quotidienne", em D. Hollier (org.), Le Collège de Sociologie. Paris, Gallimard, 60-74.

MARX, Karl, 1851-1852, O 18 de Brumário de Louis Bonaparte, a partir de Marxists Internet Archive, disponível em < http://www.dominiopublico.gov.br/download/texto/ma000066. pdf $>$ (última consulta em maio de 2016).

MAUSS, Marcel, 2003, "Uma categoria do espírito humano: a noção de pessoa, a de 'Eu'”, em M. Mauss, Sociologia e Antropologia. São Paulo, Cosac \& Naify, 367-398.

MAXWELl, Kenneth R., 1978, A Devassa da Devassa: Inconfidência Mineira, Brasil e Portugal, 1750-1808. Rio de Janeiro, Paz e Terra.

MORAES, Eliane Robert, 2012, O Corpo Impossível: A Decomposição da Figura Humana de Lautréamont a Bataille. São Paulo, Iluminuras.

PEREIRA, Edilson, 2014, O Teatro da Religião: A Semana Santa em Ouro Preto Vista através de Seus Personagens. Rio de Janeiro, Museu Nacional/Universidade Federal do Rio de Janeiro, tese de doutorado em Antropologia Social.

QUITES, Maria Regina Emery, 2006, Imagem de Vestir: Revisão de Conceitos através do Estudo Comparativo entre as Ordens Terceiras Franciscanas no Brasil. Unicamp, tese de doutorado em História.

SANCHIS, Pierre, 1983, "A caminhada ritual", Religião e Sociedade, 9: 15-26.

SCHMITT, Jean Claude, 2001, "Les masques, le diable, les morts", em J.-C. Schmitt, Le Corps, les rites, les rêves, le temps: Essais d'Anthropologie Médiévale. Paris, Gallimard, 211 $-237$.

SEVERI, Carlo, 2011, "L'espace chimérique: perception et projection dans les actes du regard”, Gradhiva, 13: 9-47.

SIMMEL, Georg, 1986, "Digresión sobre sociología de los sentidos", em G. Simmel, Sociología: Estudio sobre las Formas de Socialización. Madrid, Alianza, vol. 2., 676-695.

TAUSSIG, Michael, 1997, “Transgression”, em M. Taylor (org.), Critical Terms for Religious Studies. Chicago, The University of Chicago Press, 349-364.

TAUSSIG, Michael, 1999, Defacement. Stanford, CA, Stanford University Press.

WEBSTER, Susan Verdi, 1998, Art and Ritual in Golden-Age Spain: Sevillian Confraternities and the Processional Sculpture of Holy Week. Princeton, NJ, Princeton University Press. 